\title{
Primed Vesicles Can Be Distinguished from Docked Vesicles by Analyzing Their Mobility
}

\author{
Shahira Nofal, ${ }^{\star}$ Ute Becherer, ${ }^{\star}$ Detlef Hof, Ulf Matti, and Jens Rettig \\ Universität des Saarlandes, Physiologisches Institut, 66421 Homburg/Saar, Germany
}

\begin{abstract}
Neurotransmitters are released from nerve terminals and neuroendocrine cells by calcium-dependent exocytosis of vesicles. Before fusion, vesicles are docked to the plasma membrane and rendered release competent through a process called priming. Electrophysiological methods such as membrane capacitance measurements and carbon fiber amperometry accurately measure the fusion step of exocytosis with high time resolution but provide only indirect information about priming and docking. Total internal reflection fluorescence microscopy (TIRFM) enables the real-time visualization of vesicles, near the plasma membrane, as they undergo changes from one molecular state to the other. We devised a new method to analyze the mobility of vesicles, which not only allowed us to classify the movement of vesicles in three different categories but also to monitor dynamic changes in the mobility of vesicles over time. We selectively enhanced priming by treating bovine chromaffin cells with phorbol myristate acetate (PMA) or by overexpressing Munc13-1 (mammalian Unc) and analyzed the mobility of large dense-core vesicles. We demonstrate that nearly immobile vesicles represent primed vesicles because the pool of vesicles displaying this type of mobility was significantly increased after PMA treatment and Munc13-1 overexpression and decreased during tetanus toxin expression. Moreover, we showed that the movement of docked but unprimed vesicles is restricted to a confined region of $\sim 220 \mathrm{~nm}$ diameter. Finally, a small third population of undocked vesicles showed a directed and probably active type of mobility. For the first time, we can thus distinguish the molecular state of vesicles in TIRFM by their mobility.
\end{abstract}

Key words: exocytosis; priming; docking; TIRFM; chromaffin cell; single vesicle tracking

\section{Introduction}

Regulated exocytosis in neurons or neuroendocrine cells is the result of a cascade of events consisting of docking, priming, and finally $\mathrm{Ca}^{2+}$-dependent fusion. In neuroendocrine cells such as chromaffin cells, these different steps have been identified based on the rates at which large dense-core vesicles (LDCVs) fuse. Secretion occurs mainly in two phases: the exocytotic burst, which corresponds to the fusion of a pool of primed vesicles, and a sustained phase of exocytosis, attributable to fusion of docked vesicles that are undergoing priming on the run (Rettig and $\mathrm{Ne}$ her, 2002). The size of the pool of docked or primed vesicles can be selectively increased or decreased using pharmacological tools or by overexpressing/deleting proteins that play a role in these processes. For example, phorbol myristate acetate (PMA), a synthetic diacylglycerol analog, induces a strong increase of the burst component but leaves the sustained component unchanged (Gillis et al., 1996; Smith et al., 1998). A similar phenotype was observed by overexpressing Munc13-1 (mammalian Unc) (Ashery et al., 2000). Because the spatial distribution of the LDCVs

\footnotetext{
Received June 3, 2006; revised Dec. 5, 2006; accepted Dec. 29, 2006

This work was supported by grants from the Deutsche Forschungsgemeinschaft [Sonderforschungsbereich 530 (U.B. and J.R.) and GRK 845 (S.N. and J.R.)] and by HOMFOR. We thank U. Klemstein, K. Sandmeier, M. Schneider, C. Bick, and R. Trautmann for expert technical support.

*S.N. and U.B. contributed equally to this work.

Correspondence should be addressed to Ute Becherer, Universität des Saarlandes, Physiologisches Institut, Gebaeude 59, Kirrberger Strasse 8,66421 Homburg/Saar, Germany. E-mail: ute.becherer@uniklinik-saarland.de. D0I:10.1523/JNEUROSCI.4714-06.2007

Copyright $\odot 2007$ Society for Neuroscience $\quad$ 0270-6474/07/271386-10\$15.00/0
}

was not altered during overexpression, it was concluded that Munc13-1 acts as a priming factor. However, the evidence on which these conclusions were drawn is indirect. It would be advantageous if one could directly study the behavior of LDCVs at the plasma membrane before fusion. Total internal reflection fluorescence microscopy (TIRFM) enables the visualization of individual vesicles in vivo and in real time and is therefore an ideal tool to address these questions. This technique has been used to analyze the mobility of vesicles in a very descriptive manner in chromaffin cells (Steyer and Almers, 1999; Oheim and Stuhmer, 2000; Johns et al., 2001), in PC12 cells (Han et al., 1999; Ng et al., 2003), and in bipolar cells of the retina (Zenisek et al., 2000) but not to correlate different types of mobility of vesicles with their molecular state. Recently, the axial mobility (perpendicular to the plasma membrane) of vesicles was analyzed to study docking but not priming (Toonen et al., 2006).

We developed a new method to analyze the movement of LDCVs of chromaffin cells. With this method, we were able to identify the three different types of mobility described in previous studies (Steyer and Almers, 1999; Oheim and Stuhmer, 2000), namely immobility, restricted caged mobility, and active directed motion. Moreover, this method allows us also to assess the dynamic changes in the mobility of vesicles and define transitional states. Using PMA or Munc13-1 overexpression to promote priming, we demonstrated that the primed pool of vesicles corresponds to nearly immobile vesicles and that docked but unprimed vesicles move in a cage of $220 \mathrm{~nm}$ diameter. 


\section{Materials and Methods}

Cell preparation, virus generation, transfection, and solutions. Isolated bovine adrenal chromaffin cells were prepared as follows: after washing the adrenal glands from entrapped blood with Locke's solution, we proceeded with the digestion of the glands with Locke's solution containing 290 U/ml collagenase (Biochrom, Berlin, Germany). The adrenal medulla was then removed and cleaned from any traces of blood vessels or impurities. The medulla was grossly shredded and centrifuged at $700 \mathrm{rpm}$ for $2 \mathrm{~min}$, the supernatant was discarded, and the tissue was resuspended in Locke's solution and then minced through a nylon mesh. The obtained suspension was centrifuged three to four times at $600 \mathrm{rpm}$ for $5 \mathrm{~min}$. The supernatant was discarded, and the resultant pellet was suspended in an appropriate amount of modified DMEM. Cells were plated at a density of $3 \times 10^{5}$ cells $/ \mathrm{ml}$ in modified DMEM medium, kept at $37^{\circ} \mathrm{C}, 9 \% \mathrm{CO}_{2}$, and used 3-5 $\mathrm{d}$ after plating.

Vesicles were stained by overexpressing neuropeptide Y (NPY) fused to monomeric red fluorescent protein (mRFP). For viral expression, NPY-mRFP was cloned into pSFV1 by PCR as described previously (Ashery et al., 1999). For co-overexpression of NPY-mRFP and Munc13-1, the cDNA coding for Munc13-1-green fluorescent protein (GFP) (Ashery et al., 2000) was cloned behind NPY-mRFP separated by poliovirus (PV) internal ribosomal entry site (IRES). For cooverexpression of NPY-mRFP and tetanus toxin light chain (TeNt-LC), the cDNA coding for GFP-TeNt-LC (Borisovska et al., 2005) was cloned behind NPY-mRFP separated by PV-IRES. The constructs were verified by DNA sequencing and cloned into pSFV1. Cells were transfected $12 \mathrm{~h}$ before the start of the experiment. When a high density of marked vesicles was desirable, we overexpressed the NPY constructs by electroporation (Gene pulser II; Bio-Rad, Hercules, CA) of NPY in pDsRed-N1monomer (Clontech, Palo Alto, CA).

The bath solution used in the TIRFM experiments was as follows (in $\mathrm{mm}$ ): $140 \mathrm{NaCl}, 2.4 \mathrm{KCl}, 10 \mathrm{HEPES}, 1 \mathrm{MgCl}_{2}, 2 \mathrm{CaCl}_{2}$, and 10 glucose. Secretion was stimulated with a depolarizing solution containing the following (in $\mathrm{mm}$ ): $52.4 \mathrm{NaCl}, 90 \mathrm{KCl}, 3 \mathrm{CaCl}_{2}, 10$ glucose, and 10 HEPES. Both solutions were at $\mathrm{pH}$ 7.4, $300 \mathrm{mOsm}$. For patch-clamp measurements, the bath solution was as follows (in mM): $146 \mathrm{NaCl}, 2.4$ $\mathrm{KCl}, 10 \mathrm{HEPES}, 1.2 \mathrm{MgCl}_{2}, 2.5 \mathrm{CaCl}_{2}, 10$ glucose, and $10 \mathrm{NaHCO}_{3}, \mathrm{pH}$ $7.4(310 \mathrm{mOsm})$. The internal solution contained the following (in $\mathrm{mM}$ ): 160 Cs-aspartic acid, $10 \mathrm{HEPES}, 1 \mathrm{MgCl}_{2}, 2 \mathrm{Mg}$-ATP, and $0.3 \mathrm{Na}_{2}$-GTP, $\mathrm{pH} 7.2$ (300 mOsm). Cells were depolarized to $-5 \mathrm{mV}$ from a holding potential of $-70 \mathrm{mV}$, seven times at $5 \mathrm{~Hz}$ for $100 \mathrm{~ms}$.

The beads used in Figure 3A were PS-Speck orange fluorescent microspheres having 540/560 nm excitation/emission wavelengths and a diameter of $175 \mathrm{~nm}$ (Invitrogen, Carlsbad, CA). All chemicals were obtained from Sigma (Steinheim, Germany).

TIRFM setup. The setup consisted of an inverted Olympus Optical (Hamburg, Germany) IX 70 microscope, a solid-state laser system (85YCA010; Melles Griot, Carlsbad, CA) emitting at $561 \mathrm{~nm}$, a TILLTIRF condenser (T.I.L.L. Photonics, Gräfeling, Germany), and an Acousto Optical Tunable Filter-nC (AA Opto-Electronic, St.-Rémy-lesChevreuses, France). The excitation/emission wavelengths were selected with a dual-band FITC/Texas Red set (catalog \#51006; AHF Analysentechnik, Tübingen, Germany). The setup was equipped with a Micromax 512 BFT camera (Princeton Instruments, Trenton, NJ) controlled by MetaMorph (Visitron, Puchheim, Germany). For PMA-treated cells and cells overexpressing tetanus toxin, we used the $100 \times / 1.45$ numerical aperture (NA) TIRF objective (Olympus Optical) (pixel size, $130 \mathrm{~nm}$ ), and the acquisition rate was $10 \mathrm{~Hz}$. For cells overexpressing Munc13-1, the objective used was the $60 \times / 1.45$ NA TIRF objective (Olympus Optical) (pixel size, $144 \mathrm{~nm}$ ), and the acquisition rate was $5 \mathrm{~Hz}$. The exposure time in all cases was $100 \mathrm{~ms}$.

Tracking. Vesicles were tracked using a self-written program in LabView (National Instruments, München, Germany). All images were background subtracted and 10\% high-pass filtered with a fast Fourier transform. A threshold was set to distinguish the vesicles from the background, and then the program determined their exact position using a center of mass algorithm. If two or more trajectories collided and overlapped, the trajectories were considered only until the time of collision.
Analysis and statistics. The mean square displacement (MSD) in the $x-y$ plane was calculated as shown previously (Qian et al., 1991) (see Fig. $1 A)$. The "caging diameter" $(\mathrm{CD})$ was obtained using a routine written in Igor (WaveMetrics, Lake Oswego, OR) as follows. For each trajectory, a sliding window of $6 \mathrm{~s}$ was set in which the distance between the first position occupied by the vesicle and all the other positions within the $6 \mathrm{~s}$ window was measured, and the maximum distance reached (CD) was determined. This procedure was applied to all of the positions occupied by the vesicles throughout the $2 \mathrm{~min}$ of acquisition, and the CD was then plotted as a function of time (see Fig. $1 B$ ). Vesicles visualized for $<6 \mathrm{~s}$ were omitted. The time courses of the CDs for the different trajectories of a cell were then concatenated (see Fig. $2 B$ ), and a cumulative histogram was obtained (see Fig. 2C). Because the loading with NPY-mRFP showed not only strong cell-to-cell variability but also large variability between LDCVs of a same cell, we did not infer the $z$ position of a vesicle from its fluorescence intensity and, thus, refrained from analyzing the $z$ motion of vesicles. Statistical analysis of PMA-treated cells were performed using paired Student's $t$ test, whereas the effect of Munc13-1 overexpression and TeNt-LC overexpression was tested with unpaired Student's $t$ test in SigmaStat (Systat Software, Port Richmond, CA). The normal distribution of the data were assessed with Kolmogorov-Smirnov test. Results are shown as mean \pm SEM.

\section{Results}

Analysis of the mean square displacement versus incrementing time interval does not properly describe the mobility of vesicles with changing mobility

We analyzed the movements of LDCVs of bovine chromaffin cells that were specifically stained by overexpressing NPY fused to mRFP (Nagai et al., 2002; Duncan et al., 2003) using the Semliki Forest virus system (Ashery et al., 1999). To facilitate the tracking of single vesicles, we infected the cells for a relatively short period of time $(10-16 \mathrm{~h})$ to generate a low density $\left(0.1\right.$ vesicle/ $\left.\mu \mathrm{m}^{-2}\right)$ of stained vesicles. The LDCVs were tracked using a self-written program using the LabView development environment (for more detail, see Materials and Methods).

In general, motion of particles can be classified into four main categories: (1) the particles can be immobile; (2) the particles can move but their mobility is confined to a restricted space; (3) the particles display a free random motion as would be the case for Brownian motion; and (4) the particles move in a directed manner attributable to active transport. To distinguish between these different types of mobility, the movements of vesicles can be analyzed by plotting the MSD against incrementing time intervals (Fig. $1 A$ ). The diffusion coefficient can be determined from the slope at $x \rightarrow 0$ of this plot, allowing the distinction between immobile and mobile vesicles. Furthermore, a negative curvature of the plot indicates a restricted motion (Fig. $1 C$, middle), a linear increase of the MSD versus $\Delta t$ points to a free and random motion, and finally a positive curvature of the plot indicates an active and directed motion (Fig. $1 D$, middle). This method has been successfully used in several studies in which the mobility of secretory vesicles was analyzed (Steyer and Almers, 1999; Oheim and Stuhmer, 2000). However, this method is not applicable if the behavior of the vesicles is changing over time. An example of such a vesicle is depicted in Figure $1 E$. The lateral trajectory of the vesicle shows that the vesicle was nearly immobile at the beginning of the recording period. After $\sim 20 \mathrm{~s}$, it displayed a directed and probably active motion that lasted for $\sim 10 \mathrm{~s}$. For the last $30 \mathrm{~s}$ of the recording, the vesicle was still mobile, but the movements were restricted as if the vesicle was caught in a cage. Analysis of the MSD versus $\Delta t$ should show a linear increase, with $\Delta t$ corresponding to random walk. However, the entire movement of the vesicle is dominated by the short episode of directed mobility because the plot displays a positive curvature (Fig. $1 E$, middle). 
Hence, using this type of analysis, the mobility of vesicles with changing behavior cannot be described adequately. Moreover, this method yields only a static view of the mobility of the vesicles and by no means permits estimates of the dynamic changes of the behavior of vesicles over time.

\section{The caging diameter is an accurate method to measure the mobility of vesicles}

To overcome this shortcoming, we devised a new type of analysis that allowed us to obtain a quantitative measure of the dynamic changes of vesicle mobility. The vesicles trajectories were analyzed by an Igor routine that determined, for every time point, the $\mathrm{CD}$ as the maximal distance a vesicle travels within a fixed time window (Fig. $1 B$ ). The size of the time window was set to $6 \mathrm{~s}$ because smaller time windows gave a meaningless and noisy signal, whereas larger time windows smoothed the time course of CD too much.

Using this method to analyze the mobility of the three exemplary vesicles shown in Figure 1, it is evident that, for the vesicle with restricted mobility, the plot of the CD over time fluctuated around very low values close to $104 \mathrm{~nm}$ throughout the acquisition period (Fig. $1 C$, right). In comparison, the area in which the vesicles moved had a diameter of $126 \mathrm{~nm}$, as can be estimated from the asymptote of the MSD versus $\Delta t$ plot for $\Delta t \rightarrow \infty$. Note that, at time 0 and $30 \mathrm{~s}$, the CD was slightly larger as the vesicle moved to and from the plasma membrane. For the second vesicle (Fig. 1D) that showed a directed and active motion, the CD stays at very high values (mean is $1.1 \mu \mathrm{m}$ ) that concur with the MSD versus $\Delta t$ plot. However, the value of the $\mathrm{CD}$ fluctuates over time and reflects well the twists and turns of the trajectory of the vesicle. Finally, in contrast to the MSD versus $\Delta t$ plot, the plot of CD versus time of the third vesicle (Fig. $1 E$ ) reflects accurately the changes in mobility of this vesicle. The transient phase of directed mobility is clearly visible, as an episode in which CD is large (close to 0.8 $\mu \mathrm{m})$ that separates two phases of restricted mobility. In the first phase, the vesicle is nearly immobile with a CD of $\sim 120 \mathrm{~nm}$, whereas in the second phase a cage of $\sim 342 \mathrm{~nm}$ diameter restricts the motion.

\section{PMA restricts the mobility of vesicles}

In molecular terms, the docking process is viewed as a loose tethering of the vesicle to the plasma membrane by an unknown set of proteins, whereas the priming process is mediated by the formation of the trimeric SNARE (soluble $N$-ethylmaleimide-sensitive factor attached protein receptor) complex that supposedly immobilizes the vesicle at the release site (Bruns and Jahn, 2002; Becherer and Rettig, 2006). Although TIRFM seems to be the
A

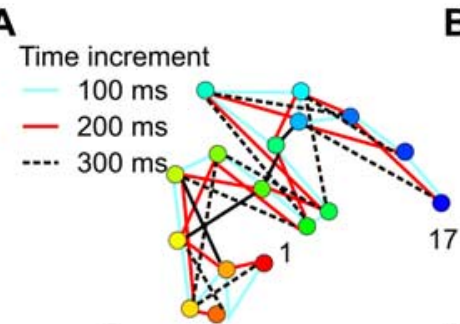

B
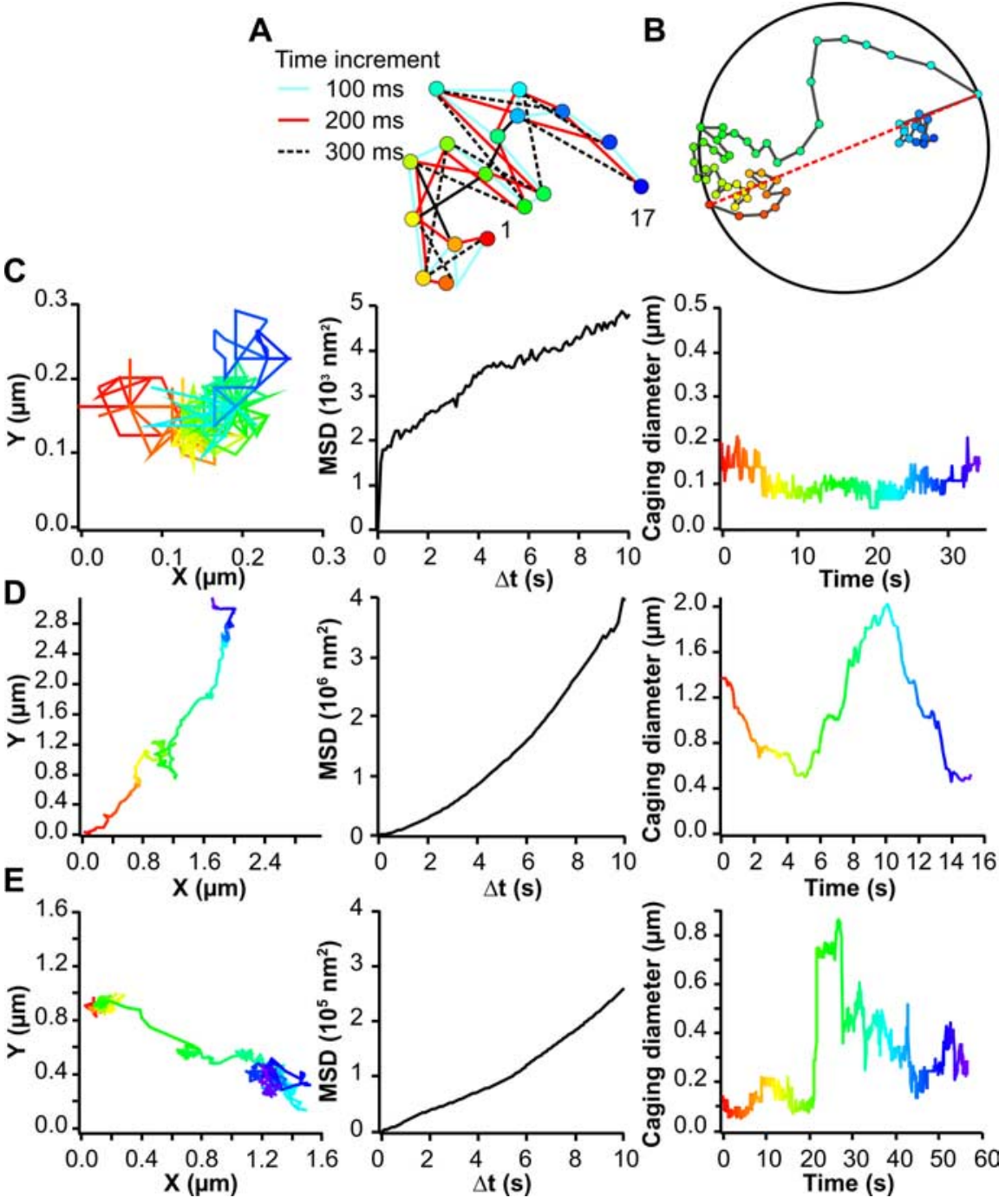

Figure 1. The CD accurately describes the movement of all vesicles. $\boldsymbol{A}$, The MSD is obtained by averaging the square distances 政 time of the vesicle shown on the left. Note that the MSD correctly interprets the motion of the vesicle in $\boldsymbol{C}$ and $\boldsymbol{D}$ but not in $\boldsymbol{E}$. Note the scaling difference between $\boldsymbol{C}(<1 \mu \mathrm{m}$ in left and right) and $\boldsymbol{D}$ and $\boldsymbol{E}(>1 \mu \mathrm{m})$.

method of choice to address this hypothesis, the large cell-to-cell variability of the mobility of the LDCVs precluded this type of analysis until now. To circumvent this problem, we devised a recording protocol that allowed us to use the cells as their own controls. In this protocol, the cells were recorded over $2 \mathrm{~min}$ at 10 $\mathrm{Hz}$, and then $250 \mathrm{~nm}$ PMA was applied for $2 \mathrm{~min}$ and subsequently washed out. The same cells were then recorded again for $2 \mathrm{~min}$ at $10 \mathrm{~Hz}$ (Fig. $2 \mathrm{~A}$, top). Finally, to ascertain their viability, the cells were stimulated with a depolarizing medium containing $90 \mathrm{~mm} \mathrm{KCl}$. Only cells that secreted in response to the stimulus were selected for analysis. Figure $2 \mathrm{~A}$ depicts the trajectories of LDCVs of a representative cell before (control) and after PMA application. It is easily seen that most large-range movements of LDCVs disappeared after PMA application. The CD analysis of the LDCV movement shows that, before PMA application, most LDCVs moved over a large distance, whereas only few vesicles 
A
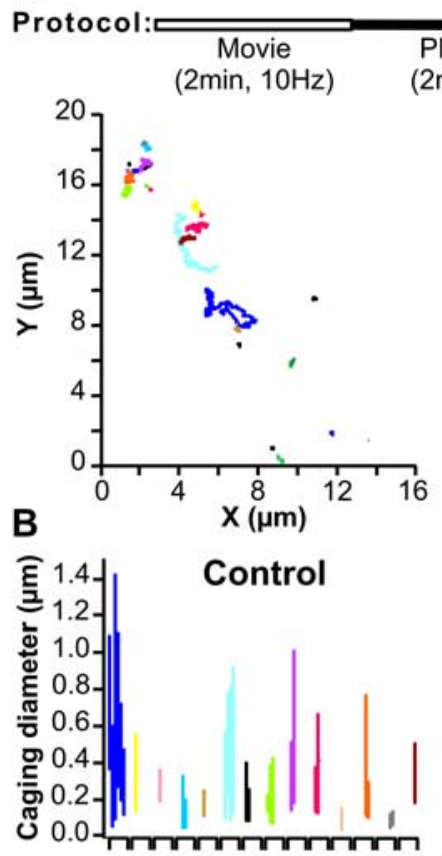

$\mathrm{C}$

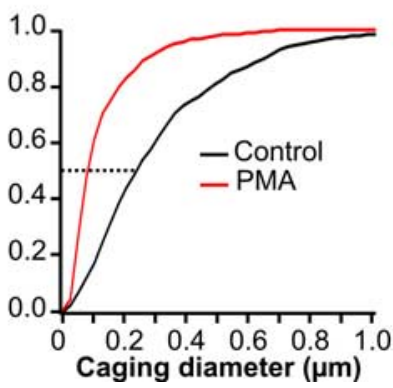

PMA Wash Movie (2min) $\quad(30-50 \mathrm{sec})(2 \mathrm{~min}, 10 \mathrm{~Hz})$ 20
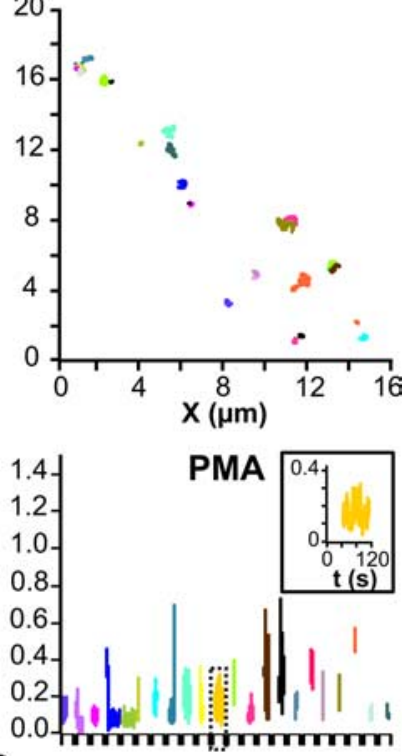

D

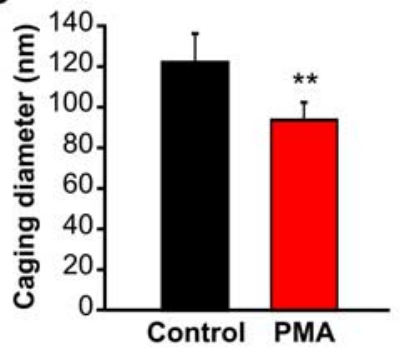

Figure 2. PMA treatment decreased the mobility of vesicles. $\boldsymbol{A}$, Top, Scheme of the protocol used in this experiment. Bottom, Trajectories of the vesicles in an exemplary cell before (control) and after PMA treatment. $\boldsymbol{B}, C D$ over time of the tracks of the vesicles shown in $\boldsymbol{A}$; inset represents the $C D$ of one vesicle over the 2 min of recording. $C$, Normalized cumulative histogram of $C D$ of vesicles of the cell shown in $\boldsymbol{A}$. Note the leftward shift after PMA treatment. D, PMA treatment significantly decreases the $50 \%$ value of the normalized cumulative histogram (dotted line in C). Results represent the mean from 21 cells ( 878 vesicles). Error bars represent SEM. ${ }^{* *} p<0.01$.

were immobile (Fig. $2 \mathrm{~B}$, right). Indeed, many LDCVs had, at least transiently, CDs exceeding $400 \mathrm{~nm}$, which means that, within $6 \mathrm{~s}$, the LDCVs had a displacement $>400 \mathrm{~nm}$. Moreover, only a small fraction of vesicles were immobile because few LDCVs had CDs near $100 \mathrm{~nm}$. After application of PMA, the mobility of LDCVs was dramatically changed (Fig. $2 B$, left). Indeed, many vesicles were nearly immobile, displaying CDs of $\sim 100 \mathrm{~nm}$, and only few moved over large distances because the CDs of most LDCVs stayed below $400 \mathrm{~nm}$. The normalized cumulative histogram of the CDs of all LDCVs of this exemplary cell shows a large leftward shift, indicating that vesicles lost mobility after PMA application compared with control conditions (before PMA application) (Fig. 2C). The 50\% value of the normalized cumulative histogram revealed a leftward shift of $156 \mathrm{~nm}$ for this exemplary cell. The average $50 \%$ value of 450 vesicles from 21 cells in each condition was significantly lower after PMA treatment compared with control $(p<0.01)$ (Fig. 2D). The leftward shift was $28.4 \pm 9.2 \mathrm{~nm}$, demonstrating that PMA treatment significantly reduced the mobility of LDCVs.

Table 1. Characteristics of tracked vesicles in PMA-treated cells

\begin{tabular}{lcc}
\hline & Control & PMA \\
\hline Number of tracked vesicles & 947 & 848 \\
Vesicles/cell & $45.1 \pm 5.5$ & $40.4 \pm 5.2$ \\
Vesicles/frame & $11.5 \pm 1.0$ & $11.4 \pm 1.0$ \\
Dwell time (s) & $23.1 \pm 1.8$ & $27.6 \pm 3.4$ \\
Average velocity (nm/s) & $331.0 \pm 20.0$ & $340.2 \pm 23.9$ \\
Number of visitors & 486 & 431 \\
Visitors/cell & $20.0 \pm 3.0$ & $20.0 \pm 3.7$ \\
\hline
\end{tabular}

$N=21, n=1795$.

It has to be noted that the mobility analysis based on CDs is restricted to vesicles that were observed in the evanescent field for $>6$ s. Notably, the "visitors," i.e., vesicles that dipped in the evanescent field for a shorter period of time, represented $\sim 50 \%$ of the total number of vesicles, in good agreement with a previous study (Toonen et al., 2006). The number of visitors was identical before and after PMA treatment (Table 1).

\section{The reduction of mobility of the vesicles is not attributable to} a reduced velocity

The average velocity of the vesicles before PMA application was $331 \pm 19 \mathrm{~nm} / \mathrm{s}$, which is in the range of values reported previously (Steyer and Almers, 1999; Oheim and Stuhmer, 2000), and is not significantly altered during PMA treatment (Table 1). Thus, the distance a vesicle moved within one time frame was similar in control conditions and after PMA treatment, but the area in which the vesicle moved was smaller after PMA treatment.

The number of vesicles seen at the footprint of the cell during the $2 \mathrm{~min}$ of the recording period was $45 \pm 5(n=21)$ in control conditions and was not changed after PMA treatment. Furthermore, the time a vesicle spent close to the membrane, referred to as dwell time, was $\sim 25 \mathrm{~s}$ in both control conditions and after PMA treatment (Table 1). Thus, as expected, PMA does not affect docking of the vesicles. However, secretion measured as the number of vesicles releasing NPY-mRFP during stimulation with a depolarizing medium containing $90 \mathrm{mM} \mathrm{KCl}$ was doubled after PMA application (data not shown). In these experiments, bovine chromaffin cells were electroporated with NPY-mRFP 2-3 d before the measurement to obtain a high density of labeled LDCVs. This result agrees well with the twofold increase of secretion measured with membrane capacitance recordings (Gillis et al., 1996; Smith et al., 1998) and confirms that PMA increases priming but not docking of LDCVs.

\section{Primed vesicles are not entirely immobile}

As mentioned above, primed vesicles are thought to be anchored tightly to the membrane by the formation of the trimeric SNARE complex, indicating that primed vesicles are entirely immobile. To test this prediction, we first assessed the inherent movement of the system using fixed beads on a coverslip to obtain a measure for immobility. The imaging of beads was performed in TIRFM at $10 \mathrm{~Hz}$, and the signal-to-noise ratio of the beads was similar to that of vesicles. The beads were tracked, and the CD versus time of their trajectory was determined. We then plotted the normalized CD distribution (Fig. 3A) and found that immobilized beads display a small jitter that can be fit by a single Gaussian function with its maximum at a $C D$ of $56 \mathrm{~nm}$. If primed vesicles were totally immobile, then their CD should display a distribution similar to that of the beads. However, when we determined the CDs of 10 vesicles in the $15 \mathrm{~s}$ before they fused with the plasma membrane, the distribution of the CDs did not exhibit a single 

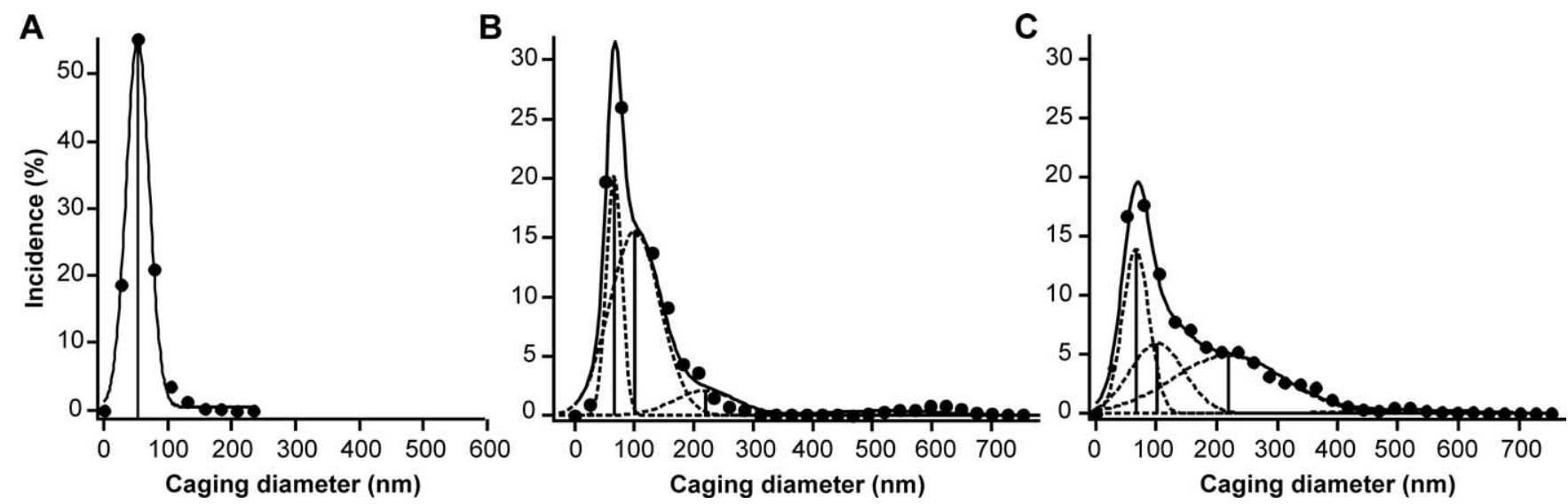

Figure 3. Classification of vesicle mobility. $\boldsymbol{A}$, Normalized distribution of CDs of fixed beads. represents the measured values, and the Gaussian fit is shown as solid line. $\boldsymbol{B}$, Normalized distribution of CDs of vesicles that fused with the plasma membrane, $N=9, n=10$ (analysis was limited to $15 \mathrm{~s}$ before fusion). The dashed lines illustrate the four individual peaks of the Gaussian fit. C, Normalized distribution of CDs of vesicles that did not fuse; $N=13, n=14$. Note that the integral of the second Gaussian is more prominent than the integral of the third Gaussian during priming $(\boldsymbol{B})$.

Gaussian distribution (Fig. 3B). Instead, the histogram was best fit by a sum of four Gaussians. A fit with three or five Gaussians gave worse results. For the first Gaussian, a good fit of the data were obtained by using the same peak value of $56 \mathrm{~nm}$ as obtained for the beads. Thus, the first Gaussian indeed represents the inherent movement of the system. The peak of the second Gaussian occurs at $101 \mathrm{~nm}$, and the peaks of the third and fourth Gaussian curves occur at 220 and $520 \mathrm{~nm}$, respectively. By integrating the Gaussian function, we find that the first and second Gaussian curves account for 25 and 58\% of the CDs, respectively, whereas the third and fourth Gaussian curves represent 10 and $7 \%$ of the CDs. Because this CD distribution plot was exclusively performed with trajectories of secreted vesicles, it seems likely that the CDs of primed vesicles correspond to the largest CD population, i.e., the second Gaussian curve. The remaining 17\% of CDs from the third and fourth Gaussian might represent some short periods of unpriming that occurred within the $15 \mathrm{~s}$ before secretion. The mean CD of the second Gaussian (101 nm) is larger than the cage size described for immobile vesicles by Oheim and Stuhmer (2000) but comparable with the cage size described by Steyer and Almers (1999). We then analyzed the distribution of CDs from vesicles that were not secreted, expecting that we could fit their CDs with the same sum of four Gaussians but that their respective weight would be shifted in favor of larger CDs.

Figure $3 C$ shows the distribution of CDs of 14 randomly chosen vesicles, which were not secreted. The data can be properly fit by the sum of four Gaussians, with peaks occurring at the same values $(56,101,220$, and $520 \mathrm{~nm})$ as the Gaussian function used for secreted vesicles. The integral of the first and the last Gaussian (30 and 6\%, respectively) are similar to those of the secreted vesicles (25 and 7\%) (Fig. 3C). Because the first Gaussian represents the inherent jitter of the system, it affects to a similar degree the mobility of vesicles whether they are secreted or not. The last Gaussian corresponds to large-distance movements and most likely represents directed and/or active type of mobility of vesicles. We consider it unlikely that docked vesicles display this type of mobility. The integral of the second Gaussian was reduced by a factor of 3, from 58 to $19 \%$, when comparing secreted vesicles to nonsecreted vesicles. In contrast, the integral of the third Gaussian is raised by a factor of 4.5 from 10 to $45 \%$, when comparing secreted vesicles with nonsecreted vesicles. Because the secreted vesicles were primed and the nonsecreted vesicles were probably docked but not necessarily primed, we can deduce that CDs of primed vesicles were included in the second Gaussian curve and that CDs of docked but unprimed vesicles were most likely represented by the third Gaussian curve. From these data, we can conclude that primed vesicles are characterized by a reduced mobility, reflected by a mean CD of $101 \mathrm{~nm}$. In contrast, docked vesicles have a larger mobility, but their movements are restricted to a cage with a mean diameter of $220 \mathrm{~nm}$.

\section{Increased priming is associated with an increase in the} number of vesicles showing a highly restricted mobility As shown in the model in Figure $4 A$, LDCVs can belong to three pools: the depot pool, the docked pool, and the primed pool. The vesicles belonging to the depot pool are located farther away from the membrane; thus, only a few of these LDCVs can be observed in the evanescent field. It is likely that the visitors belong to this pool as well as those vesicles with directed mobility. Both the docked and the primed pool of vesicles are equally visible in TIRFM but can be distinguished by the tightness of their membrane anchoring. We suggest that nearly immobile vesicles correspond to primed vesicles, and mobile vesicles moving in a cage, which we refer to as caged vesicles, correspond to docked vesicles. To test this hypothesis, we further analyzed CDs of vesicles before and after PMA treatment, by counting the number of vesicles showing one or the other type of mobility. We used the intersection point of the second and the third Gaussian curve in Figure $3 B$ $(170 \mathrm{~nm})$ to distinguish between nearly immobile vesicles and caged vesicles. To distinguish between caged vesicles and vesicles with directed mobility, we used the intersection of the third and the fourth Gaussian curve in Figure $3 B(403 \mathrm{~nm})$. To verify our selection criteria, we plotted the distribution of the CDs of all 878 vesicles we had tracked and of all vesicles before and after PMA application. In all three cases, the Gaussian curves had similar intersection points (data not shown), further confirming the validity of this method. Because many vesicles changed their type of mobility over time, we defined nearly immobile vesicles as vesicles whose CDs stayed below $170 \mathrm{~nm}$ at least $75 \%$ of the time. Vesicles with caged mobility were defined as those whose CDs remained between 170 and $403 \mathrm{~nm}$ at least $75 \%$ of the time, and vesicles with directed movements were defined as those whose CDs stayed over $403 \mathrm{~nm}$ at least $75 \%$ of the time. Furthermore, we distinguished two other groups of vesicles. The immobile- 
A

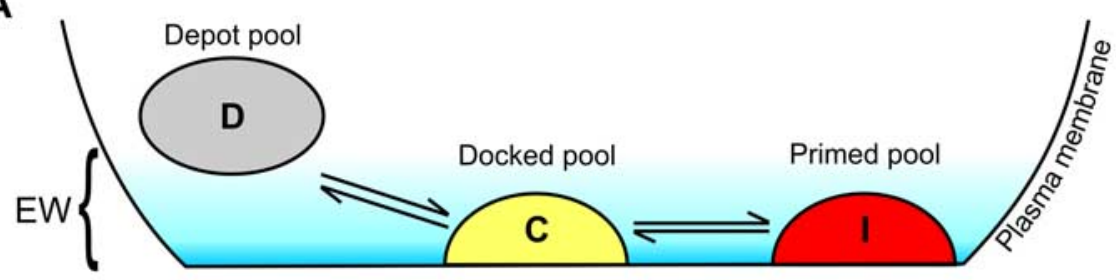

B

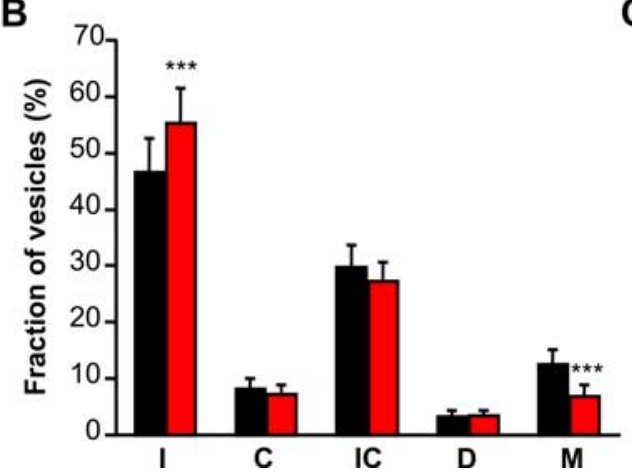

C

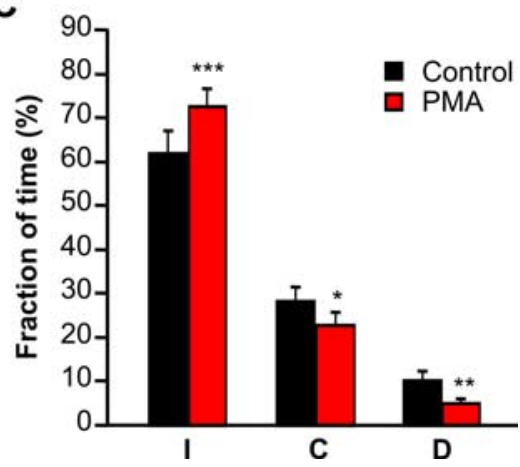

Figure 4. PMA treatment significantly increases the number of immobile vesicles. $A$, Proposed model illustrating the different pools of vesicles corresponding to distinct molecular states: primed pool, docked pool, and depot pool. We classified the vesicles into nearly immobile vesicles (I) representing the primed pool, caged vesicles (C) representing the docked pool, and vesicles having a directed motion (D) belonging to the depot pool. Immobile-caged (IC) and mixed (M) were vesicles that underwent changes between the three molecular states. EW, Evanescent wave. $\boldsymbol{B}$, Fraction of vesicles in each type of motion. $\boldsymbol{C}$, Time spent in each type of motion; $N=21, n=878$. Note the significant increase in the number of immobile vesicles after PMA treatment and the corresponding increase in the time spent in the immobile state. Error bars represent SEM; ${ }^{*} p<0.05 ;{ }^{* *} p<0.01 ;{ }^{* *} p<0.005$.

caged vesicles corresponded to vesicles that had CDs that remained at least $75 \%$ of the time below $403 \mathrm{~nm}$ but were constantly oscillating between the nearly immobile and caged mobility. Finally, a last group of vesicles, which we refer to as mixed, was found to constantly change their type of mobility and thus did not correspond to any of the criteria defined previously.

We found that, in control conditions, nearly immobile vesicles, caged vesicles, and vesicles with directed mobility accounted for $46.4 \pm 6.1,8.1 \pm 1.8$, and $3.2 \pm 1.1 \%$ of the vesicles, respectively (Fig. $4 B$ ). The ratio of nearly immobile versus caged vesicles is high, as would be expected because the newly generated vesicles, which were the vesicles labeled with NPY-mRFP, are preferentially secreted (Duncan et al., 2003). Vesicles that had a changing behavior accounted for $42.1 \pm 4.8 \%$ of the vesicles. Of these, $70.3 \pm 3.9 \%$ were immobile and caged, whereas $29.6 \pm$ $2.6 \%$ belonged to the group of mixed vesicles. During PMA treatment, the number of nearly immobile vesicles was significantly increased by $19 \%$ to $55.3 \pm 6.2 \%$ ( $p=0.0049)$ (Fig. $4 B)$. Because PMA promotes the priming of vesicles, this result clearly confirms that nearly immobile vesicles correspond to primed vesicles. Additionally, the number of mixed vesicles was significantly reduced after PMA application by $45 \%(p=0.002)$, indicating that the coherence of the mobility of vesicles was increased when priming was promoted. A similar result was obtained when we determined the fraction of time a vesicle displays one of the three types of mobility. Indeed, vesicles spend significantly more time $(p=0.002)$ in a nearly immobile state during PMA treatment compared with control conditions and significantly less time in the caged state ( $p=0.016$ ) (Fig. 4C). Additionally, the time they spend displaying a directed mobility was also significantly reduced ( $p=0.007)$. Thus, the tracked vesicles spend more time in the primed state than in the docked but unprimed state during PMA treatment.
From the data in Figure 4, $B$ and $C$, it is apparent that, because of the large cell-tocell variability, the differences in mobility before and after PMA treatment are rather small. Indeed, only the fact that the individual cells could be used as their own controls (before PMA treatment) allowed us to use the paired Student's $t$ test, which yielded significant differences. Thus, we aimed to confirm our hypothesis that nearly immobile vesicles are primed vesicles and that vesicles with caged mobility are docked but unprimed vesicles, with a second, independent set of measurements. We took advantage of the fact that Munc13-1 is an established priming factor for LDCVs whose overexpression leads to an approximate threefold increase in the number of primed vesicles in chromaffin cells (Ashery et al., 2000).

\section{Co-overexpression of Munc13-1-GFP} with NPY-mRFP does not influence its priming efficiency

To measure the effect of Munc13-1 overexpression on the mobility of LDCVs in bovine chromaffin cells, we had to coexpress NPY-mRFP to simultaneously label the LDCVs. To obtain a good staining of LDCVs, the sequence encoding NPY-mRFP was placed in front of the PV-IRES, whereas the sequence encoding Munc13-1-GFP was placed behind. To test whether coexpressing NPY-mRFP with Munc13-1-GFP lead to similar enhancement of priming as the overexpression of Munc13-1GFP alone, we measured exocytosis of cells transfected with either construct using membrane capacitance recording. We found that co-overexpression of NPY-mRFP and Munc13-1-GFP lead to a strong increase in secretion $(843.0 \pm 221.8 \mathrm{fF} ; n=6)$ compared with control cells $(252.7 \pm 57.4 \mathrm{fF})$. This increase was comparable with the increase mediated by overexpression of Munc13-1-GFP alone (1041.0 $\pm 239.8 \mathrm{fF} ; n=10)$ (Fig. 5A). In addition to the capacitance measurements, we also quantified the priming effect of Munc13-1 in TIRFM. As shown in Figure 5B, application of a solution containing $90 \mathrm{~mm} \mathrm{KCl}$ for $20 \mathrm{~s}$ resulted in the $\mathrm{Ca}^{2+}$-dependent fusion of NPY-mRFP- labeled LDCVs. Whereas in control cells $(n=11)$ these fusion events were distributed evenly over the entire $20 \mathrm{~s}$ of high $\mathrm{K}$ application, Munc13-1-overexpressing cells $(n=17)$ showed a prominent peak of secretion during the first seconds of high $\mathrm{K}$ application (Fig. 5B). This is consistent with the finding that Munc13-1 overexpression strongly increases exocytosis measured by membrane capacitance recording on a first round of flash photolysis of caged calcium but not on a second round performed $2 \mathrm{~min}$ after the first (Ashery et al., 2000). Quantifying the secretion during the first $10 \mathrm{~s}$ of high $\mathrm{K}$ application revealed that overexpression of Munc13-1 leads to an almost threefold increase in the number of fusion events visualized by TIRFM $(0.009 \pm 0.001$ and $0.003 \pm$ 0.001 events per cell and stained vesicles in Munc13-1 and control, respectively; $p<0.005)$. This value is again in excellent agreement with published values, verifying that we can use the NPY-mRFP PV-IRES Munc13-1 construct to promote priming and study the effect on LDCV mobility. 
A

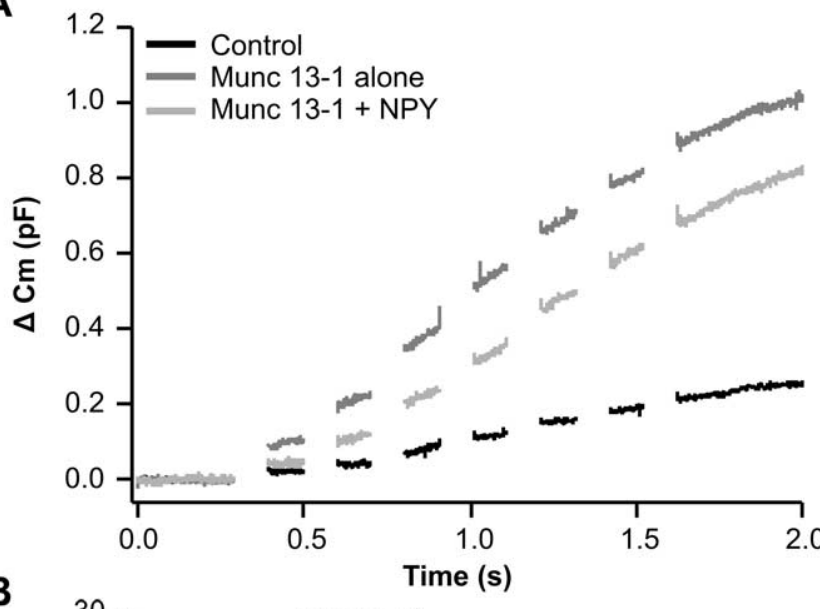

B

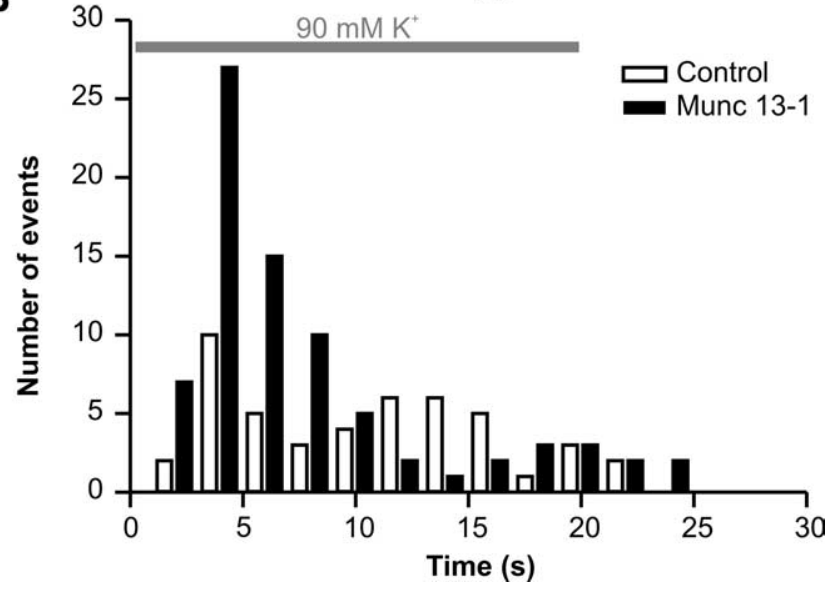

Figure 5. Co-overexpression of Munc13-1 and NPY yields a similar increase in secretion as overexpression of Munc13-1 alone using membrane capacitance and TIRFM measurements. $\boldsymbol{A}$, Capacitance recordings showing increased secretion in Munc13-1-overexpressing cells compared with control cells. $B$, Distribution of secretion events elicited by $90 \mathrm{~mm} \mathrm{KCl}$ application over time detected using TIRFM. The bin size was $2 \mathrm{~s}$ long. Munc13-1-overexpressing cells are represented in black and control cells in white. Note that most secretion events in Munc13-1overexpressing cells $(n=33)$ occurred in the first 10 s of depolarization, whereas in control cells $(n=28)$ the events were evenly distributed over the entire $20 \mathrm{~s}$ of depolarization. During this time period, the secretion of Munc13-1-overexpressing cells was approximately three times higher than in control cells.

\section{Munc13-1 overexpression also leads to a restricted mobility} of LDCVs

We recorded the movement of LDCVs for $2 \mathrm{~min}$ at $5 \mathrm{~Hz}$ using bovine chromaffin cells expressing NPY-mRFP (control, $n=24$ ) and compared them with cells co-overexpressing NPY-mRFP and Munc13-1-GFP $(n=31)$. The LDCVs were tracked as described previously. Comparable with the effect of PMA on the mobility of LDCVs, Munc13-1 overexpression affected neither the velocity of vesicles nor the vesicle dwell time at the footprint (Table 2). After measuring the CD versus time of their trajectories, we found that the normalized cumulative histogram of Munc13-1-overexpressing cells is shifted to lower values compared with control (Fig. $6 A$ ). The value at $50 \%$ of the normalized cumulative histogram is significantly smaller in Munc13-1overexpressing cells than in control cells $(100.61 \pm 5.82$ and $141.06 \pm 7.80 \mathrm{~nm}$ in Munc13-1 and control, respectively; $p<$ $0.01 ; n>700$ ), indicating a reduced LDCV mobility. Note that the $40.5 \mathrm{~nm}$ leftward shift induced by Munc13-1 overexpression is larger than the $28.4 \mathrm{~nm}$ leftward shift that was induced by PMA
Table 2. Characteristics of tracked vesicles in Munc13-1-overexpressing cells

\begin{tabular}{lcc}
\hline & Control & Munc13-1 \\
\hline Number of tracked vesicles & 1313 & 1267 \\
Vesicles/cell & $54.7 \pm 6.2$ & $36.5 \pm 4.9$ \\
Vesicles/frame & $9.4 \pm 1.0$ & $8.7 \pm 1.0$ \\
Dwell time (s) & $22.5 \pm 1.7$ & $17.8 \pm 2.0$ \\
Average velocity (nm/s) & $318.8 \pm 31.6$ & $256.6 \pm 25.5$ \\
Number of visitors & 627 & 572 \\
Visitors/cell & $26.1 \pm 3.7$ & $20.1 \pm 2.8$
\end{tabular}

Control, $N=24, n=1313 ;$ Munc13-1, $N=31, n=1267$

A

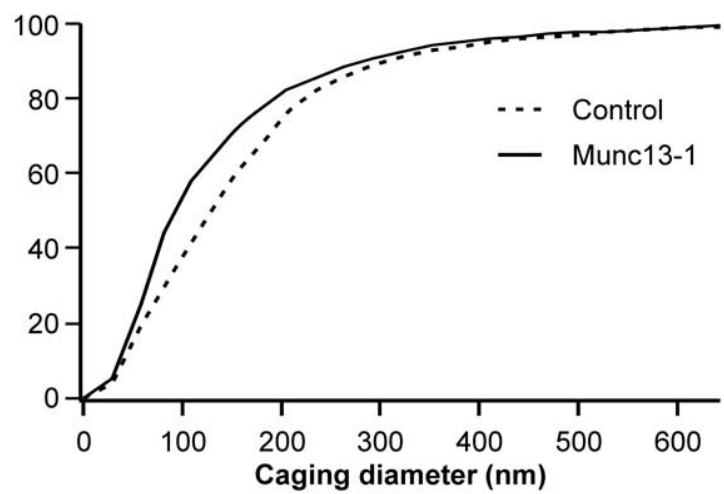

B

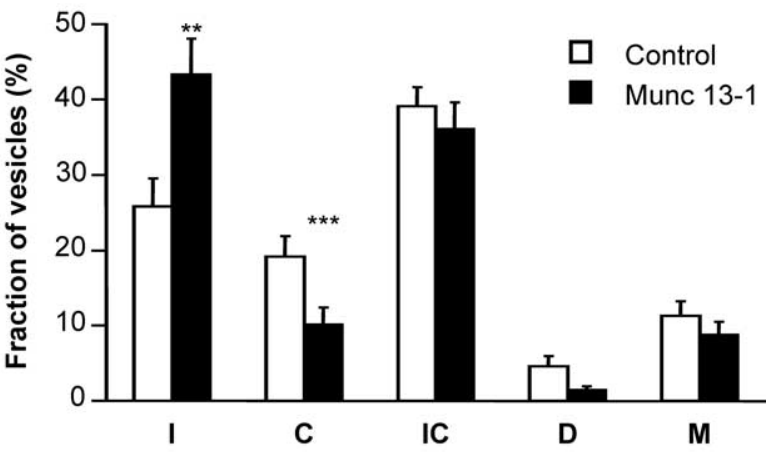

C

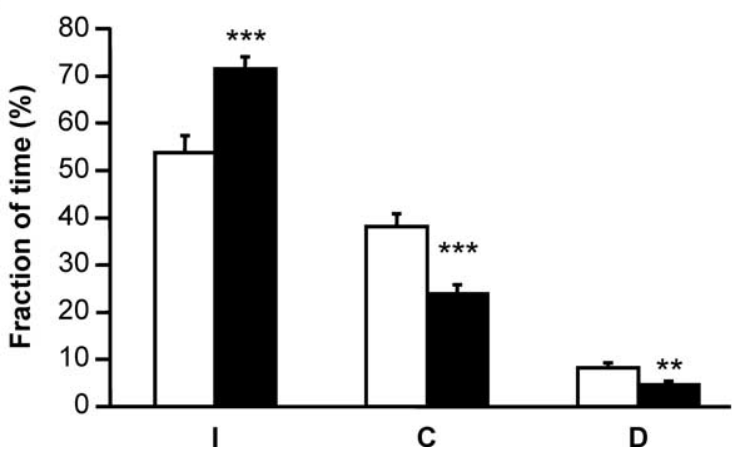

Figure 6. Vesicles of Munc13-1-overexpressing cells display lower mobility than in control cells. $A$, Normalized cumulative histogram of $C D$ in control (dotted line) and in Munc13-1overexpressing cells (solid line). The latter was significantly shifted to the left ( $p=0.05 ; \mathrm{N}=$ 24 and 31 for control and Munc13-1, respectively). $\boldsymbol{B}$, Fraction of vesicles in each type of motion. C, Fraction of time the LDCVs spent in each type of motion. Control, $N=24, n=686$; Munc13-1, $N=31, n=695$. Error bars represent SEM. ${ }^{* *} p<0.01 ;{ }^{* * *} p<0.005$. I, Immobile vesicles; $C$, caged vesicles; $\mathrm{IC}$, immobile-caged vesicles; $\mathrm{D}$, vesicles having a directed motion; $\mathrm{M}$ mixed vesicles.

treatment (Fig. 2D). This finding is compatible with previous data showing that PMA treatment had a weaker effect on pool size [i.e., priming (Gillis et al., 1996; Smith et al., 1998)] than Munc13-1 overexpression (Ashery et al., 2000). 
Table 3. Characteristics of tracked vesicles in tetanus toxin-overexpressing cells

\begin{tabular}{lcc}
\hline & Control & TeNt \\
\hline Number of tracked vesicles & 1213 & 1267 \\
Vesicles/cell & $52.5 \pm 4.3$ & $58.5 \pm 7.0$ \\
Vesicles/frame & $6.5 \pm 0.5$ & $8.4 \pm 0.9$ \\
Dwell time $(s)^{* *}$ & $17.0 \pm 1.0$ & $12.6 \pm 0.9$ \\
Average velocity $(\mathrm{nm} / \mathrm{s})$ & $532.0 \pm 27.0$ & $546.7 \pm 31.0$ \\
Number of visitors & 660 & 883 \\
Visitors/cell & $28.4 \pm 2.9$ & $37.9 \pm 5.0$ \\
\hline
\end{tabular}

Control, $N=25, n=1213 ;$ TeNt, $N=22, n=1267 .{ }^{* *} p=0.01$.

Additional analysis of vesicle mobility using the categories defined previously (nearly immobile for primed vesicles, vesicles moving in a cage for docked vesicles, and vesicles with directed mobility plus the two intermediate categories immobile-caged and mixed) revealed that the number of nearly immobile vesicles was significantly increased by $68 \%(p<0.01)$ (Fig. $6 B)$ in Munc13-1-overexpressing cells compared with control. In contrast, the number of vesicles with caged movements, hence docked but not primed vesicles, was significantly decreased by $47 \%(p=0.01)$ in Munc13-1-overexpressing cells. Importantly, the total number of docked vesicles (i.e., the sum of immobile, caged, and immobile-caged vesicles) represented $\sim 84 \pm 0.05 \%$ of the vesicles and was not altered by Munc13-1 overexpression, as expected from a protein not being involved in the docking process.

The time vesicles spend in the nearly immobile and, thus, primed state was also significantly increased by $33 \%(p<0.001)$ in cells overexpressing Munc13-1 compared with control (Fig. $6 C)$. The time the vesicles spend in the caged, thus docked, but not primed state was significantly reduced by $38 \%(p<0.001)$. The fraction of time the vesicles spend in directed motion was also significantly reduced by $43 \%(p=0.005)$ in Munc13-1overexpressing cells compared with control. However, the number of vesicles displaying this type of motion represented less then $5 \%$ of all vesicles in both cases (Fig. 6B).

Like PMA treatment, overexpression of Munc13-1 lead to a strong restriction in the freedom of movement of the LDCVs by significantly increasing the number of nearly immobile vesicles, therefore reinforcing the hypothesis that nearly immobile vesicles correspond to primed vesicles and that a caged mobility corresponds to a state in which the vesicles are docked to the membrane but not yet primed. To further test this hypothesis, we performed manipulations intended to reduce the priming rate.

\section{Preventing priming with tetanus toxin increases the lateral mobility of LDCVs}

The priming process is thought to be mediated by the formation of the trimeric SNARE complex. Hence, cleavage of vesicular SNAREs (synaptobrevin 1 and 2 and cellubrevin) by the TeNt-LC should block priming and thus lead to an increased mobility of LDCVs. We expressed GFP-TeNt-LC by infecting chromaffin cells with a Semliki Forest virus containing NPY-mRFP PV-IRES GFP-TeNt-LC. To verify the activity of TeNt-LC in this construct, we measured secretion with membrane capacitance recording from cells that were infected with the virus for $12 \mathrm{~h}$. We found that exocytosis was entirely abolished (data not shown). By tracking the vesicles from 22 cells imaged at $10 \mathrm{~Hz}$ for $2 \mathrm{~min}$, we found that, in TeNt-LC-expressing cells, the vesicle dwell time at the footprint was significantly reduced ( $p=0.01 ; n=22)$ compared with control cells (Table 3 ). This reduction was in large part attributable to a significant increase in the fraction of visitors
A

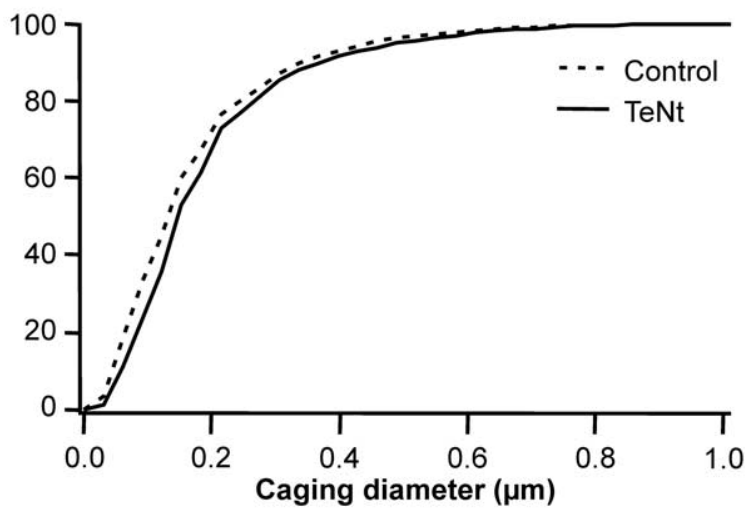

B

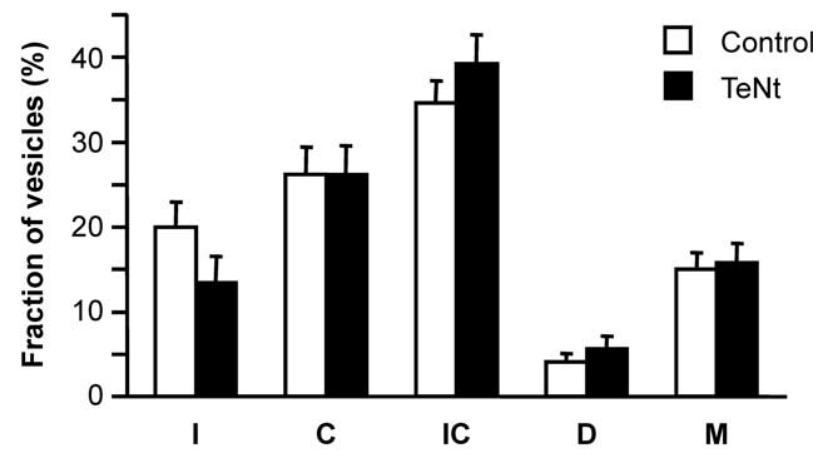

C

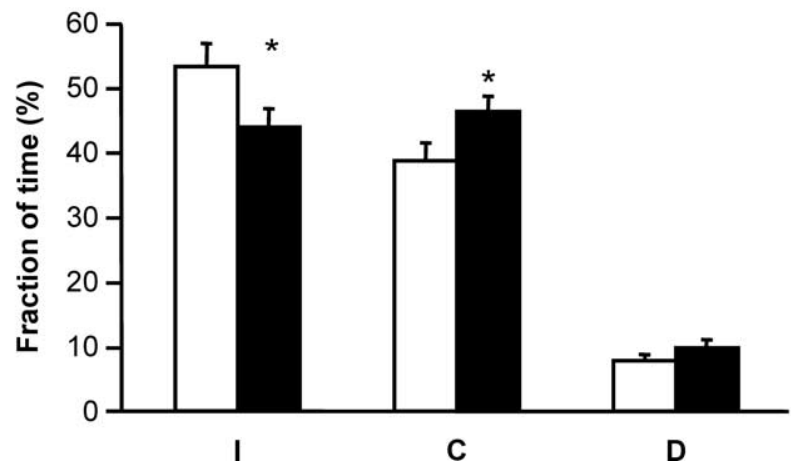

Figure 7. Vesicles of tetanus toxin-expressing cells show an increased mobility compared with vesicles in control cells. $A$, Normalized cumulative histogram of $C D$ showed a right shift in TeNt-expressing cells compared with control. The CD at $50 \%$ of the normalized cumulative histogram was significantly increased from $131.64 \pm 7.94 \mathrm{~nm}$ in control cells to $153.14 \pm 7.64$ $\mathrm{nm}$ in cells expressing TeNt $(n=453 ; p=0.03)$. $\boldsymbol{B}$, Fraction of vesicles in each type of motion. C, Fraction of time the LDCVs spent in each type of motion. Control, $N=25, n=553 ; \mathrm{TeNt}, N=$ $22, n=453$. Error bars represent SEM. ${ }^{*} p<0.05$. I, Immobile vesicles; $C$, caged vesicles; IC, immobile-caged vesicles; $D$, vesicles having a directed motion; $M$, mixed vesicles.

(LDCVs spending less then $6 \mathrm{~s}$ in the evanescent field) in TeNtLC-expressing cells $(63 \pm 3 \%)$ compared with control $(55 \pm 2 \%$; $p=0.02 ; n=25$ ) and agrees with previous findings (Johns et al., 2001). In contrast to cells treated with PMA or expressing Munc13-1, the cumulative histogram of CD of LDCVs in TeNtLC-expressing cells was shifted to the right (Fig. $7 A$ ), indicating that the mobility of LDCVs was increased during TeNt-LC expression. The shift to higher CD values at $50 \%$ was small $(21.5$ $\mathrm{nm}$ ) but significant (values at $50 \%$ were $153.14 \pm 7.64$ and $131.64 \pm 7.94 \mathrm{~nm}$ in TeNt-expressing and control cells respectively; $n=453 ; p=0.03$ ).

After classifying the LDCVs based on the type of mobility they displayed, we found that the fraction of nearly immobile vesicles was decreased in cells expressing TeNt-LC. In contrast, the frac- 
tion of vesicles with mixed immobile-caged behavior was increased, whereas the fraction of vesicles showing a caged mobility remained unchanged (Fig. $7 B$ ). Although the changes were not significant, they are opposite to the changes in mobility of the LDCVs that were observed after PMA application (Fig. $4 B$ ) or in Munc13-1-overexpressing cells compared with control (Fig. 6B). Finally, we found that the fraction of time LDCVs stayed nearly immobile was significantly reduced ( $p=0.04 ; n=453$ ) in cells expressing TeNt-LC compared with control (Fig. 7C), whereas the fraction of time they remained in the state of caged mobility was significantly increased ( $p=0.04 ; n=453$ ). Again, these results are opposite to the observed changes in mobility in PMAtreated cells (Fig. 4C) or in Munc13-1-overexpressing cells (Fig. $6 C)$. Thus, our TeNt data strongly support the data obtained during PMA application or Munc13-1 overexpression, arguing that LDCVs, which are nearly immobile, represent primed vesicles, whereas vesicles with a caged mobility represent docked but unprimed vesicles.

\section{Discussion}

In this paper, we describe a new method to analyze the movements of LDCVs in bovine chromaffin cells that allowed us to distinguish between the primed pool of vesicles and the docked but unprimed pool of vesicles based on their mobility. We based this study of the mobility of the vesicle on the maximal distance a vesicle moves within $6 \mathrm{~s}$ and termed this distance CD. With this method, we were able to distinguish between three different types of lateral mobility: (1) nearly immobile vesicles; (2) caged motion; and (3) directed motion. Previous studies using the curvature of the MSD versus $\Delta t$ plot were also able to distinguish between these types of mobility (Burke et al., 1997; Steyer and Almers, 1999; Oheim and Stuhmer, 2000; Johns et al., 2001). However, we showed that it was impossible to accurately describe the motion of vesicles that changed their mobility over time with the MSD versus $\Delta t$ plot. Changing mobility of vesicles was successfully analyzed by Oheim et al. (1999) by representing the three-dimensional (3D) diffusion coefficient of a single vesicle as a function of time. Nevertheless, this method does not allow differentiating a vesicle that is moving slowly in a constant direction from one whose motion is restricted to a confined region. Recently, Huet et al. (2006) devised a new method combining the analysis of the 3D diffusion coefficient with the analysis of the MSD curvature, and the trajectory asymmetry as a function of time was devised to examine variations in the mobility of particles. Using this method, the authors successfully distinguished between all three types of motion and could visualize the changes of mobility over time. However, computing three parameters, which have to be analyzed and compared to obtain a comprehensive information, renders this method rather complex. We showed that, using a straightforward method in which CD is plotted over time, it is not only possible to correctly describe the mobility of vesicles but also to monitor their changes in mobility. Finally, the analysis of the CDs is so robust that it is not significantly affected by a change of sampling rate from 10 to $2.5 \mathrm{~Hz}$ (data not shown). Hence, mobility of vesicles acquired at different acquisition rate $(10 \mathrm{~Hz}$ for PMA treatment of TeNt-LC expression and $5 \mathrm{~Hz}$ for Munc13-1 overexpression) can be directly compared. Furthermore, the mean CD of nearly immobile vesicles or of vesicles with caged mobility can be compared with the caging radius of a track of a vesicle estimated by the MSD technique in previous studies (Steyer and Almers, 1999; Oheim and Stuhmer, 2000) as long as their sampling rate was not below $2.5 \mathrm{~Hz}$.
Analyzing the CD of vesicles just before secretion allowed us to determine the mobility of presumptive primed vesicles. In contrast to what has been assumed previously (Oheim and Stuhmer, 2000; Huet et al., 2006), these vesicles were not entirely immobile. Although they display a strongly restricted mobility, their mean CD is approximately twice as large as the mean CD of fixed beads (mean CD is 101 and $56 \mathrm{~nm}$ for primed vesicles and fixed beads, respectively). We also found that docked but unprimed vesicles were mobile, but that a cage of $220 \mathrm{~nm}$ diameter restricted their movements.

To verify that the vesicles with strongly restricted mobility corresponded to primed vesicles, we selectively enhanced priming by treating the cells with $250 \mathrm{~nm}$ PMA or by overexpressing Munc13-1. As expected, PMA as well as Munc13-1 overexpression did not alter the number of docked vesicles but had a profound effect on the mobility of vesicles because it significantly increased the number of nearly immobile vesicles and the fraction of time they spend in this type of mobility. These results concur with previous studies (Steyer and Almers, 1999; Oheim and Stuhmer, 2000; Johns et al., 2001) showing that immobilized vesicles were preferentially secreted and thus corresponded to primed vesicles. Expression of TeNt-LC, which inhibits priming by cleavage of synaptobrevin, enhanced the mobility of vesicles by reducing the fraction of time they spend in the nearly immobile state. However, PMA treatment was shown to double and Munc13-1 overexpression to triple the fast burst component of capacitance measurements (Gillis et al., 1996; Smith et al., 1998; Ashery et al., 2000). Thus, it was hypothesized that the number of primed vesicles would be doubled. If the nearly immobile pool of vesicles represents the primed pool, we should see it increased by a factor of 2. Instead, we observed that the number of nearly immobile vesicles was raised by $19 \%$ during PMA treatment and by $68 \%$ in Munc13-1-overexpressing cells. This discrepancy with previous studies might be attributable to the fact that we were observing only newly generated vesicles, i.e., vesicles that were produced within 10-16 h preceding the experiment. These vesicles were shown to be preferentially secreted and thus primed (Duncan et al., 2003). Hence, it is likely that a large fraction of vesicles that were primed during treatment would be older vesicles that we cannot detect.

The effect of TeNt-LC was small because the interaction of synaptotagmin with syntaxin probably masked some of the priming defect (Rickman et al., 2006). However, the effect was significant. This result corresponds well with previous work (Toonen et al., 2006) showing that expression of botulinum toxin C, which specifically cleaves syntaxin, lead to an enhanced axial mobility (perpendicular to the plasma membrane) of LDCVs in chromaffin cell compared with control. However, the authors also studied the effect of TeNt-LC and could not find any significant effect on the axial mobility of LDCVs. Thus, analyzing the dynamic changes in the lateral mobility (parallel to the plasma membrane) of LDCVs appears to be the method of choice to study priming.

Our data disagree with a recent work in which Allersma et al. (2006) suggested that priming corresponds to an increased mobility of the vesicles because they observed that two priming agents, ATP and $\mathrm{Ca}^{2+}$, induced such an effect. However, increasing the intracellular ATP concentration upregulates a multitude of other ATP-dependent processes, such as vesicle transport along actin filaments mediated by myosin II or Va (Neco et al., 2004; Varadi et al., 2005). Furthermore, intracellular $\mathrm{Ca}^{2+}$ affects multiple steps during exocytosis (Voets, 2000); thus, the reported increase of mobility of nonsecreted vesicles could well be an effect on docking. However, the reason for the observed increase in 
lateral and axial mobility just before secretion remains to be elucidated.

In conclusion, we used three different manipulations of the priming reaction to demonstrate that TIRFM studies allow the distinction between two molecular states of vesicles, priming and docking, by analyzing their mobility. Our data constitute a starting point to analyze genetic manipulations of proteins that play a role in docking or priming in a quantitative manner.

\section{References}

Allersma MW, Bittner MA, Axelrod D, Holz RW (2006) Motion matters: secretory granule motion adjacent to the plasma membrane and exocytosis. Mol Biol Cell 17:2424-2438.

Ashery U, Betz A, Xu T, Brose N, Rettig J (1999) An efficient method for infection of adrenal chromaffin cells using the Semliki Forest virus gene expression system. Eur J Cell Biol 78:525-532.

Ashery U, Varoqueaux F, Voets T, Betz A, Thakur P, Koch H, Neher E, Brose N, Rettig J (2000) Munc13-1 acts as a priming factor for large dense-core vesicles in bovine chromaffin cells. EMBO J 19:3586-3596.

Becherer U, Rettig J (2006) Vesicle pools, docking, priming and release. Cell Tiss Res 326:393-407.

Borisovska M, Zhao Y, Tsytsyura Y, Glyvuk N, Takamori S, Matti U, Rettig J, Südhof T, Bruns D (2005) v-SNAREs control exocytosis of vesicles from priming to fusion. EMBO J 24:2114-2126.

Bruns D, Jahn R (2002) Molecular determinants of exocytosis. Pflügers Arch 443:333-338.

Burke NV, Han W, Li D, Takimoto K, Watkins SC, Levitan ES (1997) Neuronal peptide release is limited by secretory granule mobility. Neuron 19:1095-1102.

Duncan RR, Greaves J, Wiegand UK, Matskevich I, Bodammer G, Apps DK, Shipston MJ, Chow RH (2003) Functional and spatial segregation of secretory vesicle pools according to vesicle age. Nature 422:176-180.

Gillis KD, Mossner R, Neher E (1996) Protein kinase C enhances exocytosis from chromaffin cells by increasing the size of the readily releasable pool of secretory granules. Neuron 16:1209-1220.

Han W, Ng YK, Axelrod D, Levitan ES (1999) Neuropeptide release by efficient recruitment of diffusing cytoplasmic secretory vesicles. Proc Natl Acad Sci USA 96:14577-14582.

Huet S, Karatekin E, Tran VS, Fanget I, Cribier S, Henry JP (2006) Analysis of transient behavior in complex trajectories: application to secretory vesicle dynamics. Biophys J 91:3542-3559.

Johns LM, Levitan ES, Shelden EA, Holz RW, Axelrod D (2001) Restriction of secretory granule motion near the plasma membrane of chromaffin cells. J Cell Biol 153:177-190.

Nagai T, Ibata K, Park ES, Kubota M, Mikoshiba K, Miyawaki A (2002) A variant of yellow fluorescent protein with fast and efficient maturation for cell biological applications. Nat Biotechnol 20:87-90.

Neco P, Giner D, Viniegra S, Borges R, Villarroel A, Gutierrez LM (2004) New roles of myosin II during vesicle transport and fusion in chromaffin cells. J Biol Chem 279:27450-27457.

Ng YK, Lu X, Gulacsi A, Han W, Saxton MJ, Levitan ES (2003) Unexpected mobility variation among individual secretory vesicles produces an apparent refractory neuropeptide pool. Biophys J 84:4127-4134.

Oheim M, Stuhmer W (2000) Tracking chromaffin granules on their way through the actin cortex. Eur Biophys J 29:67-89.

Oheim M, Loerke D, Stuhmer W, Chow RH (1999) Multiple stimulationdependent processes regulate the size of the releasable pool of vesicles. Eur Biophys J 28:91-101.

Qian H, Sheetz MP, Elson EL (1991) Single particle tracking. Analysis of diffusion and flow in two-dimensional systems. Biophys J 60:910-921.

Rettig J, Neher E (2002) Emerging roles of presynaptic proteins in $\mathrm{Ca}^{++}$ triggered exocytosis. Science 298:781-785.

Rickman C, Jimenez JL, Graham ME, Archer DA, Soloviev M, Burgoyne RD, Davletov B (2006) Conserved prefusion protein assembly in regulated exocytosis. Mol Biol Cell 17:283-294.

Smith C, Moser T, Xu T, Neher E (1998) Cytosolic Ca ${ }^{2+}$ acts by two separate pathways to modulate the supply of release-competent vesicles in chromaffin cells. Neuron 20:1243-1253.

Steyer JA, Almers W (1999) Tracking single secretory granules in live chromaffin cells by evanescent-field fluorescence microscopy. Biophys 76:2262-2271.

Toonen RF, Kochubey O, de Wit H, Gulyas-Kovacs A, Konijnenburg B, Sorensen JB, Klingauf J, Verhage M (2006) Dissecting docking and tethering of secretory vesicles at the target membrane. EMBO J 25:3725-3737.

Varadi A, Tsuboi T, Rutter GA (2005) Myosin Va transports dense core secretory vesicles in pancreatic MIN6 beta-cells. Mol Biol Cell $16: 2670-2680$.

Voets T (2000) Dissection of three $\mathrm{Ca}^{2+}$-dependent steps leading to secretion in chromaffin cells from mouse adrenal slices. Neuron 28:537-545.

Zenisek D, Steyer JA, Almers W (2000) Transport, capture and exocytosis of single synaptic vesicles at active zones. Nature 406:849-854. 